\title{
Estrutura foliar de Loudetiopsis chrysothrix (Nees) Conert e Tristachya leiostachya Nees (Poaceae) ${ }^{1}$
}

\author{
JULIANA M. ALVAREZ2, ${ }^{4}$, JOECILDO F. ROCHA ${ }^{2,3}$ e SILVIA R. MACHADO ${ }^{2}$
}

(recebido: 4 de março de 2004; aceito: 23 de setembro de 2004)

\begin{abstract}
Leaf structure of Loudetiopsis chrysothrix (Nees) Conert and Tristachya leiostachya Nees (Poaceae)). Loudetiopsis chrysothrix and Tristachya leiostachya are grasses species showing great morphological similarity, but differing in stamen number and awn characteristics. However, these structures are deciduous and frequently absent in the mature espikelet, which makes their identification difficult. In order to recognize useful characters for species delimitation, this paper studied the leaf blade anatomy and ultrastructure. The different characteristics between these species were: prickle hair arrangement on the leaf blade adaxial surface; furrow depth on the adaxial surface; saliency shape on the first order bundle; vascular bundle size, position, and arrangement on the leaf blade; metaxylem vessel outline; number of cells in the bundle sheath extension; presence/absence of colourless cells in the mesophyll; number of chlorenchyma radiated cell strata and distribution of the sub epidermal scherenchyma. In both species, chloroplasts of the chlorenchyma show grana and absence of starch grains; those in the sheath are agranal, with or without starch grains. Other characteristics such as presence of epicuticular waxes, stomata in furrows on the adaxial surface, differences in the sinuosity degree of the epidermal cell wall, and cell wall structure are common in cerrado species and can be related to water saving.
\end{abstract}

Key words - cerrado, leaf structure, Loudetiopsis chrysothrix, Poaceae, Tristachya leiostachya

RESUMO - (Estrutura foliar de Loudetiopsis chrysothrix (Nees) Conert e Tristachya leiostachya Nees (Poaceae)). Loudetiopsis chrysothrix e Tristachya leiostachya são espécies de gramíneas que apresentam grande similaridade morfológica, distinguindo-se pelo número de estames e pelas características da arista. Entretanto, tais estruturas são caducas e, freqüentemente, estão ausentes na espigueta madura o que dificulta a identificação. Visando reconhecer caracteres úteis na delimitação dessas espécies, neste trabalho foram estudadas a anatomia e a ultra-estrutura da lâmina foliar. Os caracteres diferenciais entre as duas espécies foram: disposição dos tricomas tipo espinho na superfície adaxial da lâmina; profundidade dos sulcos na superfície adaxial; formato das saliências nos feixes de primeira ordem; tamanho, posição e o arranjo dos feixes vasculares na lâmina foliar; contorno dos vasos de metaxilema; número de células da extensão da bainha dos feixes vasculares; presença/ausência de células incolores no mesofilo; número de estratos de células do clorênquima radiado e distribuição do esclerênquima subepidérmico. Em ambas as espécies, os cloroplastos do clorênquima apresentam grana e ausência de grãos-de-amido; os da bainha são agranais, com ou sem grãos-de-amido. Outras características como a presença de ceras epicuticulares, estômatos alojados em sulcos na superfície adaxial, diferenças no grau de sinuosidade das paredes das células epidérmicas e na estrutura das paredes celulares são comuns a espécies de cerrados e podem estar relacionadas com a economia de água.

Palavras-chave - cerrado, estrutura foliar, Loudetiopsis chrysothrix, Poaceae, Tristachya leiostachya

\section{Introdução}

Estudos anatômicos com enfoque taxonômico em Poaceae são comuns e abordam, principalmente, os caracteres epidérmicos em vista frontal e a estrutura

1. Parte da dissertação de mestrado de J.M. Alvarez, desenvolvida no Curso de Pós-graduação em Ciências Biológicas, Área de Concentração Botânica, do Instituto de Biociências, Universidade Estadual Paulista, Campus de Botucatu.

2. Universidade Estadual Paulista, Instituto de Biociências, Departamento de Botânica, Caixa Postal 510, 18618-000 Botucatu, SP, Brasil.

3. Departamento de Botânica, Instituto de Biologia, Universidade Federal Rural do Rio de Janeiro, Caixa Postal 74582, 23851-970 Seropédica, RJ, Brasil.

4. Autor para correspondência: alvarez01@bol.com.br da lâmina foliar em seção transversal, além de considerações sobre a estrutura do cloroplasto e bainha do feixe vascular (Brown 1958, Metcalfe 1960, Johnson \& Brown 1973, Brown 1975, Ellis 1976, 1977, 1979).

Os gêneros Loudetiopsis Conert e Tristachya Nees, ambos pertencentes à família Poaceae, subfamília Panicoideae, tribo Arundinelleae, estão representados no Brasil cada um, por uma só espécie: Loudetiopsis chrysothrix (Nees) Conert e Tristachya leiostachya Nees. Ambas ocorrem principalmente em cerrados das regiões Centro-Oeste e Sudeste e, também, em campos secos e arenosos (Silberbauer-Gottsberger 1984, Longhi-Wagner 2001).

Segundo Longhi-Wagner (2001), essas duas espécies mostram grande similaridade morfológica sendo Loudetiopsis chrysothrix (Nees) Conert originalmente 
descrita como Tristachya chrysothrix Nees em 1829; posteriormente, em 1906, foi modificada para Diandrostachya chrysothrix por Jacques-Felix, sendo transferida para o gênero Loudetiopsis por Conert, em 1957. Esses taxa são diferenciados pela estrutura da espigueta, principalmente, quanto ao indumento das glumas inferiores (com tricomas dourados em Loudetiopsis chrysothrix e glabras em Tristachya leiostachya), comprimento das espiguetas e número de estames (2 em Loudetiopsis chrysothrix e 3 em Tristachya leiostachya). No entanto, em ambas, o antécio e as aristas se desprendem facilmente do restante da espigueta na maturidade, o que pode confundir a identificação (Longhi-Wagner 2001).

Visando a reconhecer estruturas foliares úteis na delimitação de Loudetiopsis chrysothrix e Tristachya leiostachya foram analisados a micromorfologia das superfícies foliares, a anatomia e a ultra-estrutura da lâmina destas duas espécies.

\section{Material e métodos}

As espécies apresentam ampla ocorrência em áreas de cerrado (sensu stricto) nos municípios de Botucatu

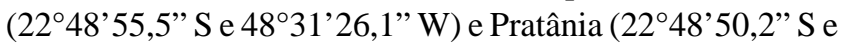
48 44’35,8” W), Estado de São Paulo. As exsicatas encontram-se depositadas no herbário BOTU, registradas sob os números: Loudetiopsis chrysothrix (Nees) Conert (23.388, 23.404, 23.405) e Tristachya leiostachya Nees (23.389, 23.407).

Amostras retiradas do terço médio da lâmina de folhas do terceiro nó, contado a partir da inflorescência, foram processadas para estudos anatômicos e ultra-estruturais, conforme descrito a seguir.

Microscopia fotônica (MF) - O material foi fixado em FAA 50 (Johansen 1940) durante $48 \mathrm{~h}$, sendo posteriormente transferido para etanol $70^{\circ} \mathrm{GL}$ e seccionado transversalmente com micrótomo manual tipo Ranvier. As seções com $10 \mu \mathrm{m}$ de espessura foram clarificadas em hipoclorito de sódio a $20 \%$ da solução comercial, coradas com azul de astra e safranina, montadas entre lâmina e lamínula com glicerina 50\% e lutadas com esmalte, segundo técnicas usuais descritas em Kraus \& Arduin (1997). A descrição das características anatômicas foi baseada na terminologia de Metcalfe (1960) e Ellis (1976, 1979). Microscopia eletrônica de varredura (MEV) - Para análise da micromorfologia das superfícies foliares, as amostras foram coletadas e imediatamente distendidas entre lâminas de vidro e secadas à sombra, à temperatura ambiente; posteriormente, foram metalizadas com carbono e ouro e analisadas ao microscópio eletrônico de varredura Philips SEM-515.

Microscopia eletrônica de transmissão (MET) - Para análise das características ultra-estruturais do clorênquima, feixes vasculares e aparelho estomático, as amostras foram fixadas

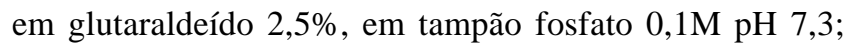
pós-fixadas em tetróxido de ósmio a $1 \%$ no mesmo tampão (2h); desidratadas em série crescente de soluções de acetona e embebidas em Araldite. As seções ultrafinas, obtidas em ultramicrótomo Leica, foram contrastadas com solução saturada de acetato de uranila (Watson 1958) e citrato de chumbo (Reynolds 1963) e examinadas ao microscópio eletrônico de transmissão Philips CM 100 (MET).

\section{Resultados}

Os caracteres estruturais mais representativos das superfícies foliares das duas espécies, em vista frontal, são mostrados nas figuras 1 a 18 .

Superfície abaxial - Células longas intercostais retangulares (figuras 2, 3, 8) mais longas que largas, de paredes finas e sinuosas, assim como as células interestomáticas, cujas extremidades são côncavas e silicificadas, nas duas espécies; as sinuosidades das paredes são mais pronunciadas em Tristachya leiostachya Nees (figura 4). Células curtas intercostais solitárias ou aos pares, ocorrendo também células silicificadas e suberificadas (figuras 1, 3). Células longas costais retangulares, com paredes finas e sinuosas, estão dispostas em uma a três fileiras longitudinais em Loudetiopsis chrysothrix (Nees) Conert e quatro a oito em Tristachya leiostachya, de acordo com o tamanho dos feixes vasculares. Ceras epicuticulares, em forma de bastonetes, estão presentes na lâmina de Loudetiopsis chrysothrix (figura 7). Aparelhos estomáticos ovóides a subdiscoidais, células subsidiárias em forma de domo, silicificadas (figuras 1-4), distribuídas geralmente em uma única fileira longitudinal na zona intercostal (figuras 7, 8, 9); quando em duas, são separadas por uma fileira de células longas e curtas intercaladas. Macropelos rígidos, com paredes espessas e silicificadas, antrorsos, dispostos em fileiras nos bordos

Figures 1-4. Loudetiopsis chrysothrix and Tristachya leiostachya abaxial leaf blade surface (FM). 1. L. chrysothrix. Rows of stomata (e) and silicified cells: dumb bell shaped (h), cross shaped (c), horizontally elongated and crenate outline (a) and cork cells (arrow). 2. L. chrysothrix. Interstomatal long cells (ie) and long cells (cl) with slightly undulating wall. 3. T. leiostachya. Rows of stomata (e), interstomatal long cells (ie), long cells (cl) and short cells (cc) in the intercostal zone. 4. T. leiostachya. Detail showing interstomatal long cells (ie) and long cells (cl) with wall deeply undulating. Bars $=70 \mu \mathrm{m}(1,2,3), 30 \mu \mathrm{m}(4)$. 


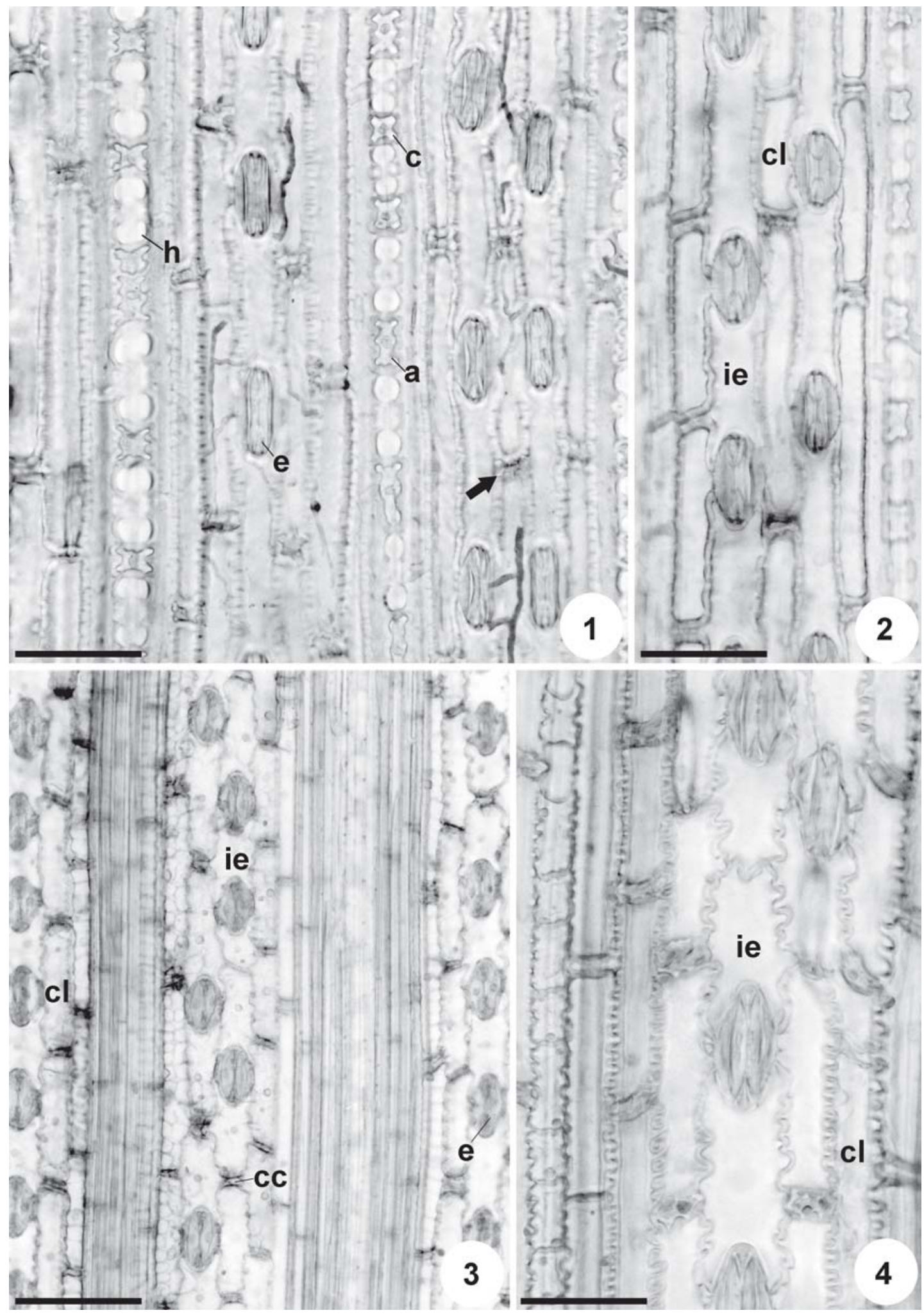

Figuras 1-4. Superfície abaxial da lâmina foliar de Loudetiopsis chrysothrix e Tristachya leiostachya (MF). 1. L. chrysothrix. Fileiras de estômatos (e) e de células silicificadas halteriformes (h), em forma de cruz (c), alongada e crenada horizontalmente (a) e células suberosas (seta). 2. L. chrysothrix. Células interestomáticas (ie) e células longas (cl) com paredes levemente sinuosas. 3. T. leiostachya. Fileira de estômatos (e), células interestomáticas (ie), células longas (cl) e células curtas (cc) na zona intercostal. 4. T. leiostachya. Detalhe mostrando células interestomáticas (ie) e células longas (cl) com paredes fortemente sinuosas. Barras $=70 \mu \mathrm{m}(1,2,3), 30 \mu \mathrm{m}(4)$. 


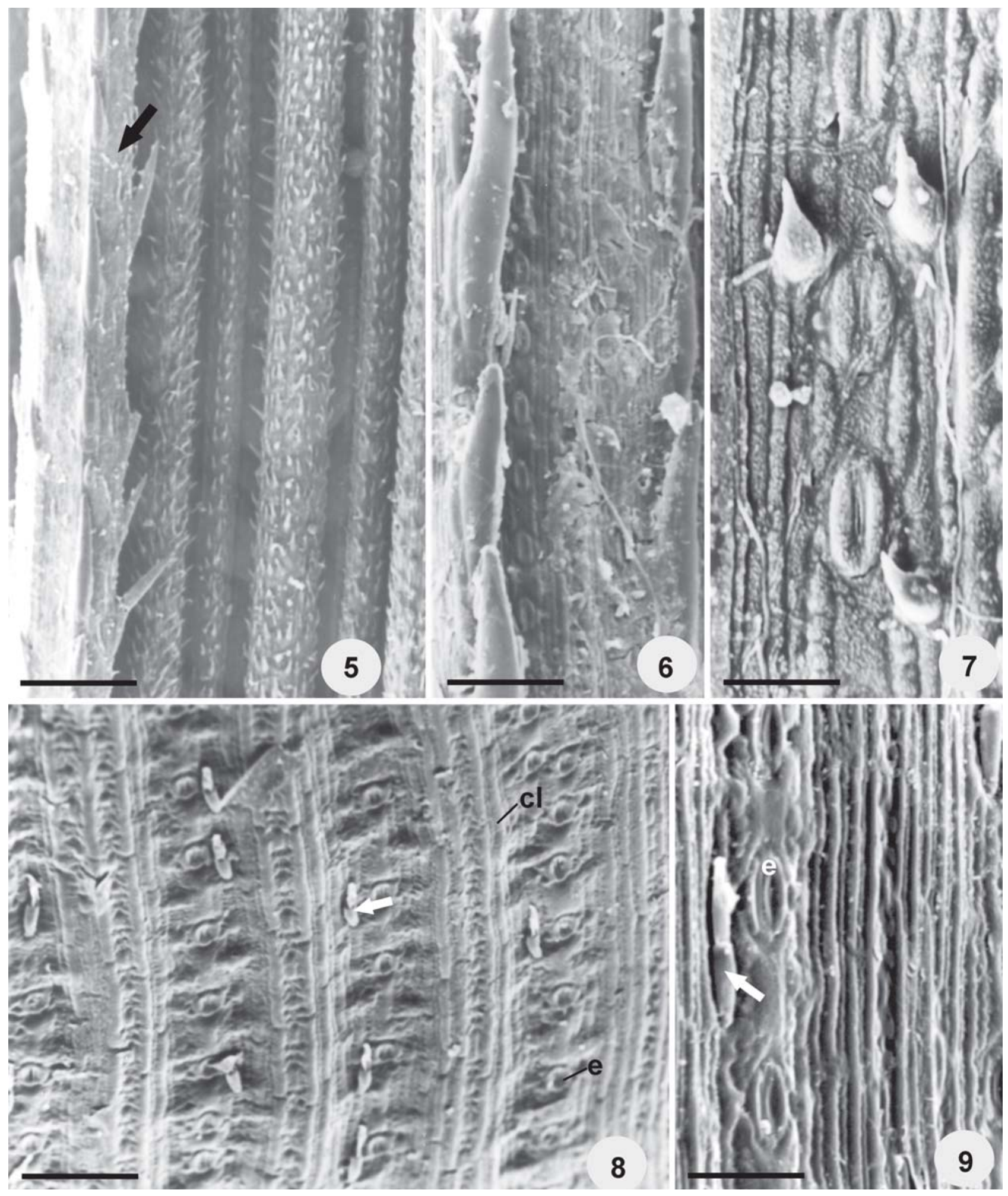

Figuras 5-9. Superfície abaxial da folha de Loudetiopsis chrysothrix e Tristachya leiostachya (MEV). 5. L. chrysothrix. Bordo da lâmina convoluta (seta) com quatro fileiras de macropelos. 6. L. chrysothrix. Macropelos em detalhe. 7. L. chrysothrix. Estômatos, tricomas tipo gancho e células longas na zona intercostal. 8. T. leiostachya. Estômatos (e), micropelos tipo panicóide (seta) e células longas (cl) na zona intercostal da lâmina. 9. T. leiostachya. Detalhe mostrando micropelo tipo panicóide (seta) e estômatos (e). Barras = $260 \mu \mathrm{m}$ (5), $90 \mu \mathrm{m}$ (6), $30 \mu \mathrm{m}$ (7), 70 m (8), $46 \mu \mathrm{m}$ (9). 
da lâmina foliar (figuras 5, 6), sendo quatro fileiras em Loudetiopsis chrysothrix (figura 5) e uma fileira em Tristachya leiostachya; macropelos curtos e largos e macropelos longos e estreitos, ocorrem em fileira única, na zona intercostal da lâmina foliar de Loudetiopsis chrysothrix. Micropelos bicelulares, do tipo panicóide com célula apical aculiforme em Loudetiopsis chrysothrix (figuras 8, 9). Tricomas tipo gancho unicelulares, pequenos e com a base globosa, na lâmina foliar de Loudetiopsis chrysothrix (figura 7), dispostos em fileiras nas zonas costal e intercostal. Células silicificadas em fileiras, sempre associadas aos feixes vasculares; o número de fileiras varia de um a quatro em Loudetiopsis chrysothrix e de um a três em Tristachya leiostachya, conforme a largura da zona costal: quatro fileiras sobre os feixes vasculares primários, duas fileiras sobre os feixes vasculares secundários e uma fileira sobre os feixes vasculares terciários em Loudetiopsis chrysothrix; três fileiras sobre os feixes vasculares primários e duas fileiras sobre os feixes secundários em Tristachya leiostachya, estando ausentes na zona intercostal em ambas as espécies; apresentam formato variável incluindo os tipos halteriforme, em forma de cruz, alongado e crenado horizontalmente (figura 1).

Superfície adaxial -Células longas intercostais e costais, aparelho estomático, células curtas e células silicificadas similares aos da superfície abaxial, nas duas espécies. Estômatos localizados na região mais profunda da zona intercostal, lateralmente às células buliformes (figuras 12, 17). Células buliformes protuberantes, localizadas na parte mediana da zona intercostal (figuras 13, 18). Papilas epidérmicas presentes sobre as nervuras, em ambas as espécies. Micropelos unicelulares, antrorsos, sobre as nervuras de maior calibre em Loudetiopsis chrysothrix (figura 11). Tricomas tipo espinho de paredes espessadas, antrorsos e prostrados, sobre as nervuras de menor calibre em Loudetiopsis chrysothrix (figuras 11, 14) e antrorsos e retrorsos sobre todas as nervuras em Tristachya leiostachya (figuras 16, 17). Micropelo bicelular, tipo panicóide com célula apical aculiforme em Loudetiopsis chrysothrix e célula apical falsiforme (figuras 17, 18) ou digitiforme em Tristachya leiostachya. Ceras epicuticulares na forma de bastonetes presentes nas duas espécies (figuras 12, 18).

Os caracteres anatômicos e ultra-estruturais mais representativos da lâmina foliar, em seção transversal, das duas espécies estão apresentadas nas figuras 10 , 15, 19-23, 24-28.

Lâmina foliar convoluta em Loudetiopsis chrysothrix e ligeiramente plana em Tristachya leiostachya. Saliências (zona costal) e sulcos (zona intercostal) (figuras 10,15) proeminentes na superfície adaxial, em correspondência com os feixes vasculares; superfície abaxial levemente ondulada, em correspondência com os feixes de menor calibre; sulcos com profundidade média (até 1/4 da espessura do limbo) em Loudetiopsis chrysothrix (figuras 10, 21), sendo pouco profundos (menos de 1/4) em Tristachya leiostachya (figuras 15, 19); saliências achatadas sobre os feixes vasculares em Loudetiopsis chrysothrix e arredondadas em Tristachya leiostachya. Quilha ausente a pouco pronunciada. Vascularização composta por feixes de três calibres (feixes de primeira, segunda e terceira ordens) em Loudetiopsis chrysothrix (figura 21) e de dois calibres (feixes de primeira e segunda ordens) em Tristachya leiostachya (figura 19). Nervura mediana formada por um feixe vascular de primeira ordem, em ambas as espécies. Feixes vasculares em arranjo regular a partir do meio em direção ao bordo da lâmina, ocorrendo sucessivamente um feixe de terceira ordem entre um de primeira e de segunda ordem em Loudetiopsis chrysothrix (figuras 10, 21); em Tristachya leiostachya ocorrem três feixes de segunda ordem entre dois de primeira ordem (figura 19). Em Loudetiopsis chrysothrix os feixes vasculares de primeira e segunda ordens ocupam posição central na lâmina, enquanto que os de terceira ordem são restritos aos sulcos e situam-se próximos da superfície abaxial. Em Tristachya leiostachya todos os feixes estão posicionados no centro da lâmina. O contorno dos feixes de primeira ordem é elíptico em Loudetiopsis chrysothrix (figura 22) e largamente oboval em

Figures 5-9. Loudetiopsis chrysothrix and Tristachya leiostachya abaxial leaf surface (SEM). 5. L. chrysothrix. Leaf margin convolute (arrow) with four rows of macro hairs. 6. L. chrysothrix. Macro-hairs in detail. 7. L. chrysothrix. Stomata, hooks hairs and long cells in the intercostal zone. 8. T. leiostachya. Stomata (e), Panicoid type micro-hairs (arrow) and long cells (cl) in intercostal zone of the leaf blade. 9. T. leiostachya. Detail showing Panicoid type micro-hair (arrow) and stomata (e). Bars = $260 \mu \mathrm{m}$ (5), $90 \mu \mathrm{m}$ (6), $30 \mu \mathrm{m}$ (7), $70 \mu \mathrm{m}$ (8), $46 \mu \mathrm{m}$ (9). 


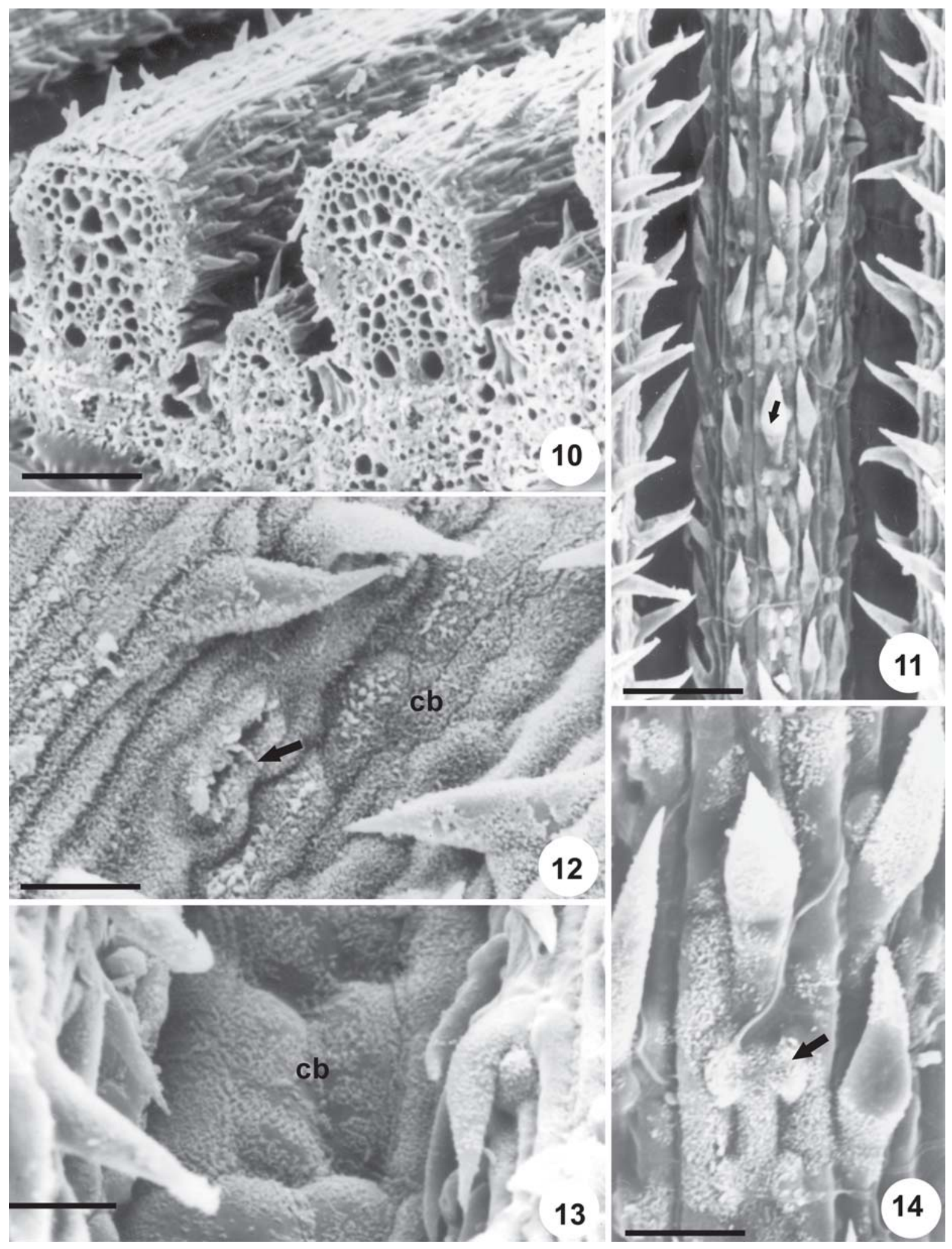

Figuras 10-14. Lâmina foliar de Loudetiopsis chrysothrix (MEV). 10. Seção transversal. 11-14. Superfície adaxial, em vista frontal. 10. Aspecto geral mostrando saliências (zona costal) e reentrâncias (zona intercostal). 11. Micropelos unicelulares antrorsos e tricomas tipo espinho (seta) antrorsos sobre a zona costal. 12. Células buliformes (cb), estômato (seta) e micropelos na zona intercostal recobertos por ceras epicuticulares. 13. Células buliformes papiliformes (cb) e micropelos. 14. Tricoma tipo espinho e célula silicificada (seta) halteriforme na zona costal recobertos por ceras epicuticulares. Barras $=80 \mu \mathrm{m}(10), 70 \mu \mathrm{m}$ (11), $20 \mu \mathrm{m}(12,13,14)$. 
Tristachya leiostachya (figura 19); os de segunda ordem são elípticos nas duas espécies, enquanto que os de terceira ordem, presentes somente em Loudetiopsis chrysothrix são cilíndricos. Feixes colaterais com grupos distintos de xilema e floema; xilema e floema de contorno angular nos feixes de terceira ordem; vasos do metaxilema distintos somente nos feixes de primeira ordem, de contorno angular em Loudetiopsis chrysothrix e circular em Tristachya leiostachya; nas duas espécies, floema completamente envolvido por esclerênquima nos feixes de primeira ordem. Bainha do feixe vascular dupla, interrompida em alguns pontos (figuras 19, 22); a externa, clorofilada, formada por células parenquimáticas conspícuas de paredes relativamente espessadas (figuras 22, 24), com cloroplastos volumosos e alongados, agranais, de posição centrífuga, com grãos-de-amido elipsóides (figura 24); bainha interna completa nos feixes de primeira ordem (figura 22) e reduzida nos demais feixes (figura 23). Extensão da bainha do feixe vascular, de natureza parenquimática, somente na superfície adaxial (figuras 19, 21, 22); ampla (tri ou multisseriada) nos feixes de primeira ordem, uni ou bisseriada nos feixes de segunda ordem e ausente nos de terceira ordem em Loudetiopsis chrysothrix; bisseriada nos de primeira ordem e bi ou unisseriada nos feixes de segunda ordem em Tristachya leiostachya. Mesofilo constituído por clorênquima e células incolores em Loudetiopsis chrysothrix (figura 23) e unicamente por clorênquima em Tristachya leiostachya (figura 20). Clorênquima radiado nas duas espécies (figuras 19, 21, 24, 25), com uma fileira de células tabulares justapostas em torno de cada feixe vascular em Loudetiopsis chrysothrix (figuras 23, 24), sendo os feixes contíguos separados por colunas de células incolores (figura 23); com duas fileiras de células em torno de cada feixe (a interna, formada por células isodiamétricas pequenas e, a externa, por células tabulares maiores) em Tristachya leiostachya (figuras 19, 20, 25) e cloroplastos elípticos, conspícuos, sem grãosde-amido, com grana desenvolvido (figura 26). Células incolores, presentes somente em Loudetiopsis chrysothrix, ocorrem em colunas associadas às células buliformes na superfície adaxial e às células epidérmicas comuns na superfície abaxial; para cada grupo de células buliformes, ocorrem duas colunas de células incolores, dispostas uma de cada lado do feixe vascular de terceira ordem (figura 23). Esclerênquima subepidérmico, descontínuo, sobre os feixes vasculares e no bordo da lâmina; na superfície adaxial, esclerênquima em faixas estreitas formadas por duas a três camadas de fibras sobre os feixes de primeira e segunda ordens em Loudetiopsis chrysothrix (figura 22); em pequenos grupos sobre os feixes em Tristachya leiostachya (figura 19); na face abaxial da lâmina de ambas as espécies, o esclerênquima é mais desenvolvido e fica em contato com a bainha esclerenquimática do feixe vascular de primeira ordem (figuras 19, 22). No bordo da lâmina foliar, o esclerênquima ocorre na forma de um casquete relativamente pequeno, encurvado com extensão curta em direção à superfície adaxial em Loudetiopsis chrysothrix (figura 21); em Tristachya leiostachya, o casquete é bem mais desenvolvido, amplo, pontiagudo, com extensão para a superfície abaxial (figura 19). Células epidérmicas comuns de tamanhos e formatos variáveis, com parede tangencial externa espessa e lignificada na superfície abaxial, sendo mais delgada na adaxial. Cutícula mais espessa na superfície abaxial, delgada na adaxial e imperceptível sobre as células buliformes. Papilas globosas sobre as nervuras na superfície adaxial nas duas espécies (figura 23). Células buliformes maiores que as células epidérmicas comuns, em número de três a cinco células agrupadas em forma de leque, na superfície adaxial (zona intercostal) (figuras 20, 23), preenchidas com substâncias fenólicas. Estômatos presentes em ambas as superfícies foliares; na superfície abaxial, se localizam na direção das células incolores em Loudetiopsis chrysothrix (figura 22) e entre os feixes vasculares em Tristachya leiostachya (figura 20); na superfície adaxial, situam-se na zona intercostal, nas adjacências das células buliformes (figuras 21, 23); apresentam câmaras sub e epiestomática bem delimitadas (figura 27); célulasguarda com paredes periclinais fortemente espessadas (figura 28), com quatro estratos distintos: a) ceras

Figures 10-14. Loudetiopsis chrysothrix leaf blade (SEM). 10. Transverse section. 11-14. Adaxial surface in frontal view. 10. General aspect showing ribs (costal zone) and furrows (intercostal zone). 11. Unicellular, antrorse micro hairs and antrorse prickle hairs (arrow) on the costal zone. 12. Bulliform cells (cb), stomata (arrow) and micro hairs in intercostal zone covered by epicuticular waxes. 13. Papilliform bulliform cells (cb) and micro hairs. 14. Prickle hair and silicified dumb bell shaped cells (arrow) in costal zone covered by epicuticular waxes. Bars = $80 \mu \mathrm{m}$ (10), $70 \mu \mathrm{m}$ (11), $20 \mu \mathrm{m}(12,13,14)$. 

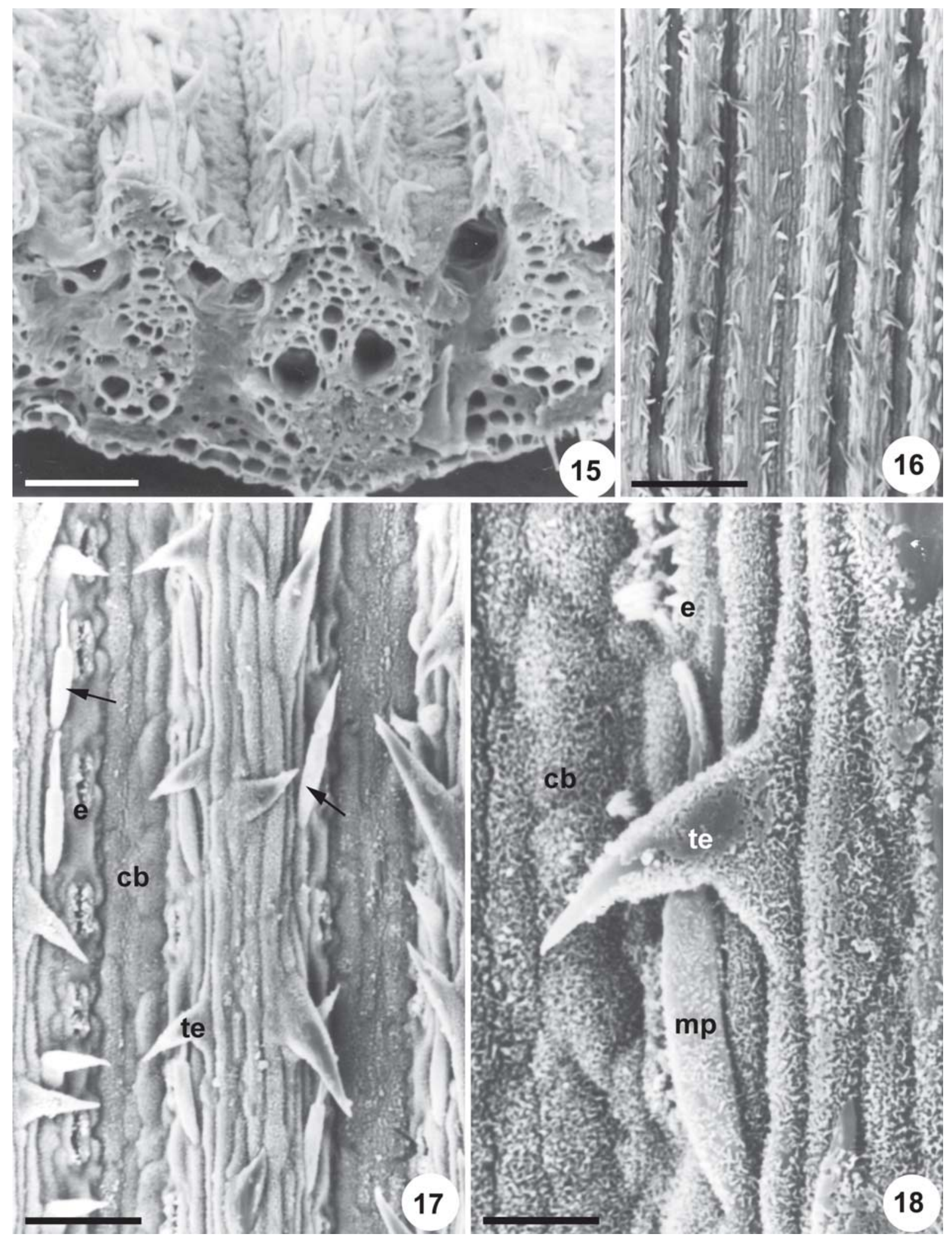

Figuras 15-18. Lâmina foliar de Tristachya leiostachya (MEV). 15. Seção transversal. 16-18. Superfície adaxial. 15. Aspecto geral mostrando saliências (zona costal) e reentrâncias (zona intercostal). 16. Aspecto geral mostrando tricomas tipo espinho antrorsos e retrorsos. 17. Detalhe mostrando tricomas tipo espinho (te), micropelos do tipo panicóide (setas), estômatos (e) e células buliformes (cb) recobertos por ceras. 18. Detalhe mostrando tricoma tipo espinho (te), micropelo tipo panicóide (mp), estômato (e) e células buliformes (cb) recobertos por ceras. Barras = $80 \mu \mathrm{m}$ (15), $230 \mu \mathrm{m}$ (16), $50 \mu \mathrm{m}$ (17), $14 \mu \mathrm{m}$ (18). 
epicuticulares, na forma de túbulos ou filamentos; b) cutícula propriamente dita, delgada, de aspecto homogêneo, elétron-lucente; c) camada cuticular, espessa, de aspecto heterogêneo, elétron-densa e com impregnação de ceras, cutina e pectina da qual partem finas ramificações em direção a cutícula e, d) camada celulósica, espessa e lignificada. Os três primeiros estratos formam uma projeção sobre o poro estomático, originando uma crista que delimita a câmara epiestomática (figura 27). A cutícula propriamente dita é bastante espessada na região do poro estomático (figura 27), a qual pode obstruir completamente esta região (figura 28).

As principais características da lâmina foliar que diferenciam Loudetiopsis chrysothrix de Tristachya leiostachya estão resumidas na tabela 1 .

\section{Discussão}

As duas espécies estudadas pertencem à subfamília Panicoideae, tribo Arundinelleae (Longhi-Wagner 2001), sendo os caracteres epidérmicos observados típicos para os gêneros Loudetiopsis e Tristachya (Metcalfe 1960, Watson \& Dallwitz 1992).

As características epidérmicas verificadas nas folhas de Loudetiopsis chrysothrix e Tristachya leiostachya, incluindo a presença de micropelos panicóides, células silicificadas halteriformes e em forma de cruz dispostas em longas fileiras, estômatos com células subsidiárias em forma de domo, xilema e floema de forma angular nos feixes de pequeno porte e clorênquima radiado em torno dos feixes vasculares, são típicas de Panicoideae. Já, macropelos inseridos superficialmente na superfície epidérmica e presença de bainha do feixe vascular dupla, completa ou incompleta, como verificado nas duas espécies, são características típicas de Festucoideae (Metcalfe 1960). Segundo Metcalfe (1960), poucas espécies de gramíneas apresentam uma mistura de características panicóides e festucóides e, freqüentemente, estão mais relacionadas ao grupo panicóide.

Nas duas espécies estudadas, as células longas costais e intercostais diferem quanto ao tamanho e sinuosidade da parede anticlinal. De acordo com Watson (1942) existem duas hipóteses principais que tentam explicar a sinuosidade da parede anticlinal da célula longa; uma delas, sugere que tensões entre o mesofilo e a epiderme causam as sinuosidades enquanto que a outra, mais plausível, afirma que o endurecimento diferenciado da cutícula é responsável por essa característica. Embora Fisher (1939 apud Ellis 1979) tenha relacionado a sinuosidade da parede com a prevenção de colapso da parede celular durante a falta de água, não se sabe ao certo a vantagem dessa característica. Kaufman et al. (1969) relataram que são bastante comuns as variações quanto ao tamanho, forma e ondulações da parede dessas células em uma mesma zona intercostal. Metcalfe (1960) e Ellis (1979) ressaltaram a necessidade do uso de outros caracteres adicionais no auxílio à taxonomia, devido a variações genotípicas e fenotípicas que essas células sofrem.

Células silicificadas tipo halteriforme, como observadas no presente trabalho, foram relatadas por Sendulsky \& Labouriau (1966) para as duas espécies estudadas. Tanto em Loudetiopsis chrysothrix como em Tristachya leiostachya foi observada silicificação das células epidérmicas incluindo células interestomáticas, células subsidiárias e macropelos do bordo da lâmina foliar. Silicificação generalizada de células epidérmicas em espécies de gramíneas do cerrado foram relatadas por diferentes autores (Sendulsky \& Labouriau 1966, Campos \& Labouriau 1969, Söndahl \& Labouriau 1970, Figueiredo \& Handro 1971). Segundo Campos \& Labouriau (1969), a silicificação maciça da epiderme foliar pode ter conseqüências ecológicas significativas relacionadas às relações hídricas da planta com a atmosfera e com o balanço hídrico.

A distribuição dos estômatos em fileiras nas bases dos sulcos, onde ficam protegidos quando a folha perde água e se enrola, é característica de espécies que ocorrem em ambientes secos (Metcalfe 1960, Lyshede 1982). A presença de uma projeção da parede das células-guarda sobre o poro estomático, delimitando uma câmara epiestomática, representa um tipo adicional de proteção do estômato. Ainda em espécies xerófitas, os

Figures 15-18. Tristachya leiostachya leaf blade (SEM). 15. Transverse section. 16-18. Adaxial surface. 15. General aspect showing ribs (costal zone) and furrows (intercostal zone). 16. General aspect showing antrorse and retrorse prickle hairs. 17. Detail showing prickle hairs (te), Panicoid type micro hairs (arrows), stomata (e) and bulliform cells (cb) covered by epicuticular waxes. 18. Detail showing prickle hair (te), Panicoid type micro hair (mp), stomata (e) and bulliform cells (cb) covered by waxes. Bars = $80 \mu \mathrm{m}$ (15), $230 \mu \mathrm{m}$ (16), $50 \mu \mathrm{m}$ (17), $14 \mu \mathrm{m}$ (18). 


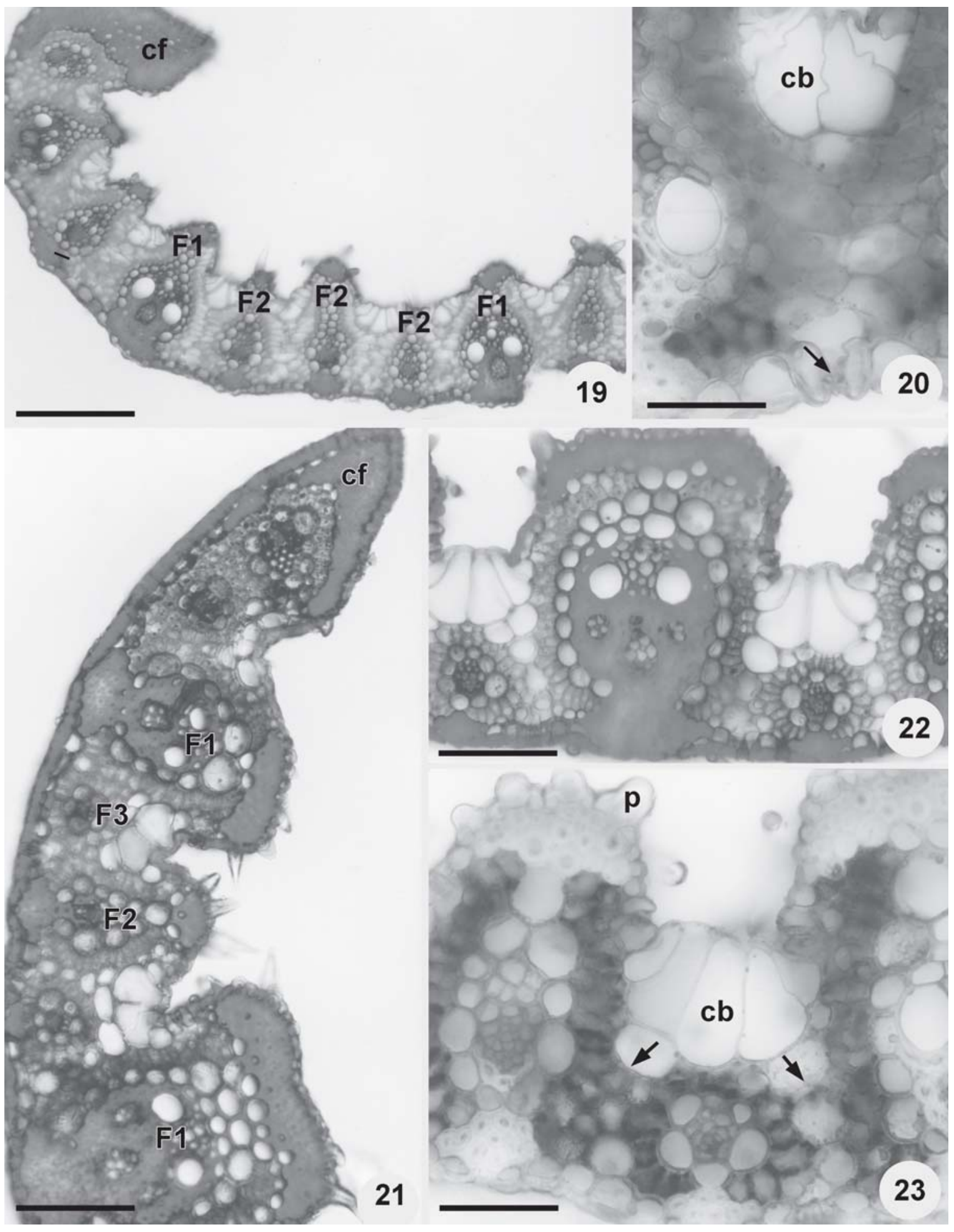

Figuras 19-23. Lâmina foliar de Tristachya leiostachya e Loudetiopsis chrysothrix em seção transversal (MF). T. leiostachya. 19. Aspecto geral mostrando feixes vasculares de primeira $\left(\mathrm{F}_{1}\right)$ e segunda ordens $\left(\mathrm{F}_{2}\right)$ e bordo com casquete (cf) de fibras com extensão abaxial. 20. T. leiostachya. Células buliformes em forma de leque (cb), estômato (seta) com células subsidiárias amplas e câmara subestomática na superfície abaxial. 21. L. chrysothrix. Aspecto geral mostrando feixes vasculares de primeira $\left(\mathrm{F}_{1}\right)$, segunda $\left(\mathrm{F}_{2}\right)$ e terceira ordens $\left(\mathrm{F}_{3}\right)$ e bordo com casquete de fibras (cf) com extensão adaxial. 22. L. chrysothrix. Detalhe mostrando feixe vascular de primeira ordem com bainha parenquimática externa e bainha interna. 23. L. chrysothrix. Papilas globosas (p) sobre os feixes vasculares, coluna de células incolores (setas) no mesofilo e células buliformes (cb). Barras $=140 \mu \mathrm{m}$ (19), $30 \mu \mathrm{m}$ (20), $70 \mu \mathrm{m}$ (21, 22), $30 \mu \mathrm{m}$ (23). 
estômatos podem estar protegidos por tricomas e depósitos de ceras epicuticulares (Ihlenfeldt \& Hartmann 1982), como verificado no presente trabalho. Segundo os estudos de Brown \& Johnson (1962), com relação às particularidades das células-guarda em seção transversal, as duas espécies estudadas apresentam características intermediárias entre Panicoideae e Festucoideae. A estrutura da parede periclinal externa das células estomáticas é complexa e provavelmente reflete as condições de água e de temperatura do ambiente, estando relacionadas com a economia de água (Lyshede 1982).

A ocorrência generalizada de ceras epicuticulares na superfície da lâmina foliar, principalmente ao redor ou sobre os estômatos das duas espécies estudadas, é uma característica freqüentemente associada com redução da perda de água através da transpiração, impedimento da entrada excessiva de água da chuva e controle das trocas gasosas, bem como com a restrição da perda de nutrientes essenciais e substâncias orgânicas pela lixiviação. Além disso, as ceras epicuticulares criam um micro-ambiente favorável para uma grande variedade de organismos parasitas e saprófitos, atuam como uma barreira contra patógenos e influenciam a recepção e subsequente redistribuição da radiação incidente (Baker 1982).

Metcalfe (1960) reportou a existência de uma correlação positiva entre saliências e sulcos bem desenvolvidos com a capacidade de involução da folha, tendo considerado tal aspecto como um caráter evolutivo em resposta às condições ecológicas, que também são úteis em diagnósticos específicos. Em Loudetiopsis chrysothrix a lâmina é convoluta e possui sulcos com diferentes graus de profundidade. Além disso, o esclerênquima subepidérmico, principalmente no bordo da lâmina, juntamente com as células buliformes podem participar no enrolamento das folhas (Shields 1951).

A distribuição do esclerênquima associado aos feixes vasculares apresenta valor taxonômico e ecológico, pois gramíneas de ambientes áridos apresentam esclerênquima bastante desenvolvido, enquanto que nas espécies tropicais o esclerênquima ocorre em pequenos grupos não associados aos feixes vasculares (Metcalfe 1960, Ellis 1976). Assim, no presente trabalho as particularidades observadas no padrão de distribuição do esclerênquima podem auxiliar na distinção de Loudetiopsis chrysothrix e Tristachya leiostachya.

Os estudos anatômico e ultra-estrutural da lâmina foliar mostraram que em ambas as espécies o mesofilo apresenta organização típica de representantes de Panicoideae com anatomia Kranz. De acordo com Johnson \& Brown (1973), a anatomia Kranz é uma característica de mais da metade das Panicoideae e, apesar de algumas variações, são facilmente reconhecidas pela disposição radial do clorênquima em torno dos feixes vasculares. Além disso, as células do clorênquima possuem paredes delgadas e os cloroplastos são granais desprovidos de amido, enquanto que os cloroplastos presentes na bainha parênquimática são agranais de disposição centrífuga com ou sem grãos-de-amido (Johnson \& Brown 1973). Os cloroplastos das células do mesofilo variam em tamanho e posição, mas todos se caracterizam por apresentar grana bem desenvolvido, como ressaltado por Ellis (1977); contudo, podem ocorrer variações no conteúdo granal dos cloroplastos da bainha Kranz (Johnson \& Brown 1973). Variações no número de camadas de clorênquima são freqüentes entre as diferentes subfamílias e, segundo Johnson \& Brown (1973), mesofilo com uma só camada de células representa uma redução extrema. Nas duas espécies estudadas, embora pertencentes à mesma subfamília, verificou-se diferença no número de camadas do clorênquima.

Entre as características geralmente associadas com a anatomia Kranz encontram-se a capacidade das plantas em realizar fotossíntese na presença de concentrações elevadas de $\mathrm{O}_{2}$, baixa fotorrespiração, baixa taxa de transpiração e grande capacidade de

Figures 19-23. Tristachya leiostachya and Loudetiopsis chrysothrix leaf blade in transverse section (FM). 19. T. leiostachya. General aspect showing first $\left(\mathrm{F}_{1}\right)$ and second order $\left(\mathrm{F}_{2}\right)$ vascular bundles and margin with hood of sclerenchyma (cf) with abaxial extension. 20. T. leiostachya. Fan shaped bulliform cells (cb), stomata (arrow) with large subsidiary cells and sub stomatal chamber on abaxial surface. 21. L. chrysothrix. General aspect showing first $\left(\mathrm{F}_{1}\right)$, second $\left(\mathrm{F}_{2}\right)$ and third order $\left(\mathrm{F}_{3}\right)$ vascular bundles and margin with hood of sclerenchyma (cf) with adaxial extension. 22. L. chrysothrix. Detail showing first order vascular bundle with parenchyma sheath external and sheath internal. 23. L. chrysothrix. Globose papillae (p) on the vascular bundle, column of colourless cells (arrows) in the mesophyll and fan-shaped bulliform cells (cb). Bars = 140 $\mu m(19)$, $30 \mu \mathrm{m}(20), 70 \mu \mathrm{m}(21,22), 30 \mu \mathrm{m}(23)$. 


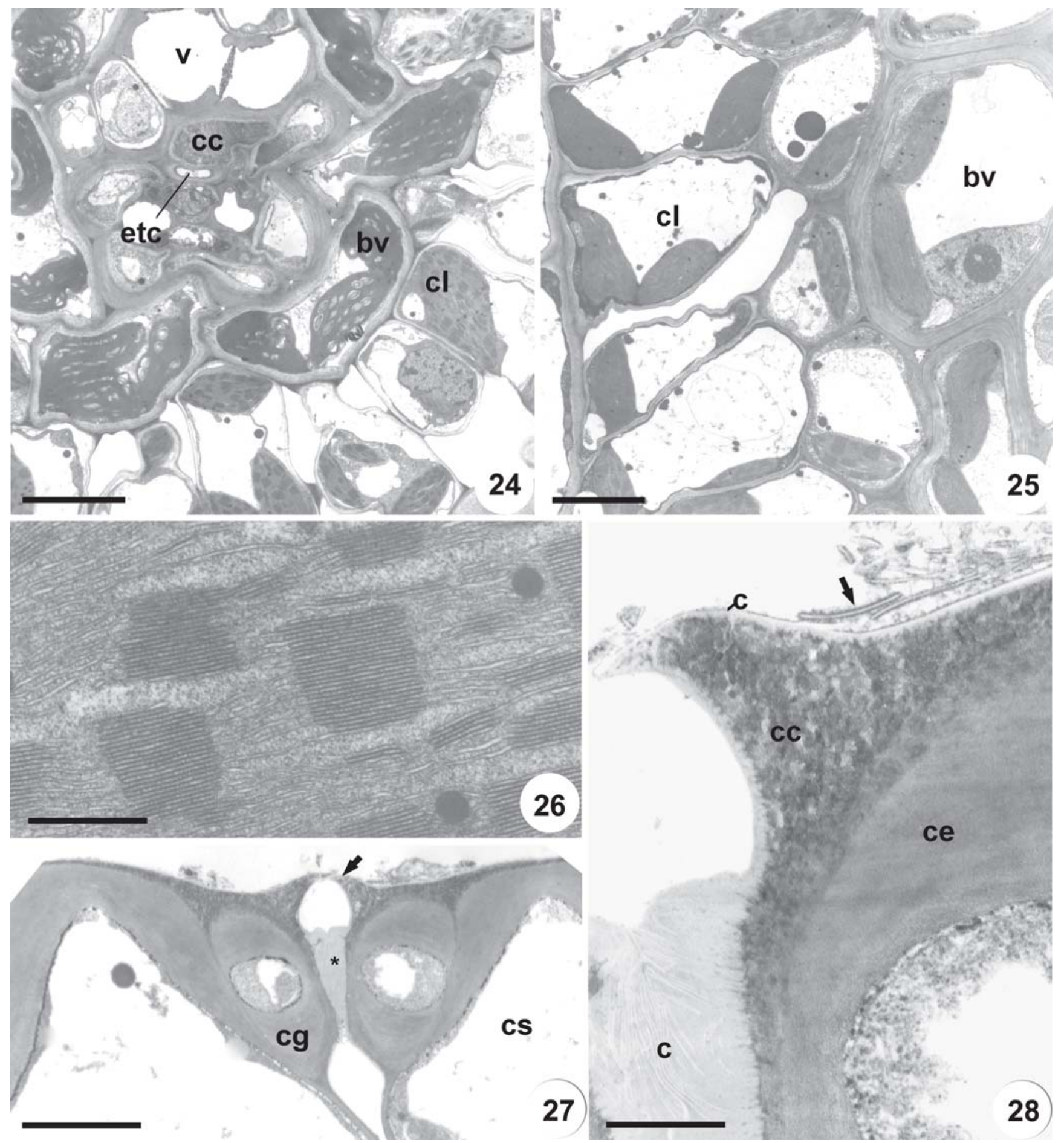

Figuras 24-28. Aspectos ultra-estruturais da lâmina foliar de Loudetiopsis chrysothrix e Tristachya leiostachya (MET). 24. L. chrysothrix. Células do clorênquima radiado (cl) em torno da bainha do feixe vascular (bv). Elemento de vaso (v). Elemento de tubo crivado (etc). Célula companheira (cc). 25. T. leiostachya. Células do clorênquima radiado (cl) em torno da bainha do feixe vascular (bv). 26. Detalhe mostrando grana em cloroplasto do mesofilo. 27. L. chrysothrix. Aparelho estomático em seção transversal mediana com células subsidiárias (cs), células-guarda (cg), poro obstruído (*), câmara supra-estomática e câmara subestomática. A seta indica crista epiestomática. 28. L. chrysothrix. Detalhe das células guarda mostrando ceras epicuticulares (seta), cutícula (c), camada cuticular (cc) e camada celulósica (ce). Observar cutícula (c) espessa obstruindo

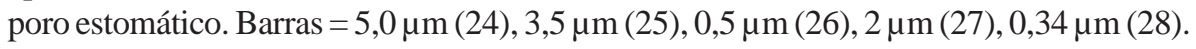


Tabela 1. Características diferenciais da lâmina foliar de Loudetiopsis chrysothrix (Nees) Conert e Tristachya leiostachya Nees (Poaceae). $\left(\mathrm{F}_{1}=\right.$ feixe vascular de primeira ordem; $\mathrm{F}_{2}=$ feixe vascular de segunda ordem; $\mathrm{F}_{3}=$ feixe vascular de terceira ordem).

Table 1. Leaf blade differential characteristics of Loudetiopsis chrysothrix (Nees) Conert and Tristachya leiostachya Nees (Poaceae). ( $F_{1}=$ first order vascular bundle; $F_{2}=$ second order vascular bundle; $F_{3}=$ third order vascular bundle).

\begin{tabular}{lll}
\hline Estruturas & Loudetiopsis chrysothrix & Tristachya leiostachya \\
\hline Tricomas aculiformes & Antrorsos & Antrorsos e retrorsos \\
Profundidade dos sulcos & Até $1 / 4$ & Menos de 1/4 \\
Saliências sobre $\mathrm{F}_{1}$ & Achatadas & Arredondadas \\
Vascularização & Feixes de três tamanhos $\left(\mathrm{F}_{1}, \mathrm{~F}_{2}\right.$ e $\left.\mathrm{F}_{3}\right)$ & Feixes de dois tamanhos $\left(\mathrm{F}_{1}\right.$ e $\left.\mathrm{F}_{2}\right)$ \\
Posição dos feixes vasculares & $\mathrm{F}_{1} \mathrm{e} \mathrm{F}_{2}$ posição central e $\mathrm{F}_{3}$ próximos à & $\mathrm{F}_{1}$ e $\mathrm{F}_{2}$ em posição central na lâmina \\
& superfície abaxial & foliar \\
Arranjo dos feixes vasculares & Um $\mathrm{F}_{3}$ entre $\mathrm{F}_{1}$ e $\mathrm{F}_{2}$ sucessivamente & Três $\mathrm{F}_{2}$ entre dois $\mathrm{F}_{1}$ sucessivamente \\
Contorno dos vasos do metaxilema & Angular & Circular \\
Extensão da bainha do feixe vascular & Em $\mathrm{F}_{1}$ multisseriada, $\mathrm{F}_{2}$ uni ou bisseriada, & Em $\mathrm{F}_{1}$ bisseriada, $\mathrm{F}_{2}$ uni ou bisseriada \\
& $\mathrm{F}_{3}$ ausente & \\
Clorênquima & Radiado, uniestratificado & Radiado, biestratificado \\
Células incolores no mesofilo & Presentes & Ausentes \\
Distância intervenal & Duas células & Quatro células \\
Esclerênquima associado aos feixes & Faixas estreitas & Grupos pequenos \\
vasculares & & \\
Esclerênquima no bordo & Encurvado, com extensão para a superfíciee & Pontiagudo, com extensão para a \\
& adaxial & superfície abaxial \\
\hline
\end{tabular}

desenvolvimento em condições adversas. Segundo Johnson \& Brown (1973), estas características podem estar associadas ao fato de, com poucas exceções, as espécies xéricas de Panicoideae Kranz parecem conservar os estômatos fechados durante a maior parte do tempo. De acordo com os autores, nesta situação, a perda de água é reduzida e a entrada do $\mathrm{CO}_{2}$ se dá, principalmente, via cutícula. Assim, a obstrução do poro estomático pela cutícula, como observado em Loudetiopsis chrysothrix, pode representar um mecanismo que evita a perda de água em condições adversas.

As características da lâmina foliar, em seção transversal, das duas espécies estudadas, em geral, são condizentes com a descrição anatômica para ambos os gêneros (Metcalfe 1960), exceto a ocorrência de bainha dupla no feixe vascular de Tristachya leiostachya referida como sendo simples pelo autor. Ellis (1977) registrou a ocorrência tanto de bainha simples como bainha dupla para o gênero Loudetiopsis e, somente de bainha simples para o gênero Tristachya, ambas consideradas como possuindo anatomia Kranz. De acordo com Ellis (1977), variações na estrutura da bainha do feixe vascular são freqüentes no gênero Loudetiopsis, sendo encontrados tanto representantes formadores de malato (tipo NADP-ME, com bainha simples), quanto representantes formadores de aspartato (tipo PCK, com bainha dupla).

Hattersley (1986) relata que os gêneros pertencentes a tribo Arundinelleae apresentam bainha simples e são formadoras de malato (tipo NADP-ME); contudo nas duas espécies estudadas, a presença de

Figures 24-28. Ultrastructural aspects of Loudetiopsis chrysothrix and Tristachya leiostachya leaf blade (TEM). 24. L. chrysothrix. Radiated chlorenchyma cells (bv) around the vascular bundle sheath (bv). Vessel element (v). Sieve tube element (etc). Companion cell (cc). 25. T. leiostachya. Radiated chlorenchyma cells (cl) around the vascular bundle sheath (bv). 26. T. leiostachya. Detail showing grana in the mesophyll chloroplast. 27. L. chrysothrix. Stomatal complex in median transverse section, with subsidiary cells (cs), guard cells (cg), ocluded pore (*), supra and sub stomatal chambers. The arrow indicates outer stomatal ledge. 28. L. chrysothrix. Detail of guard cell showing epicuticular waxes (arrow), cuticle (c), cuticular layer (cc), and cellulosic layer

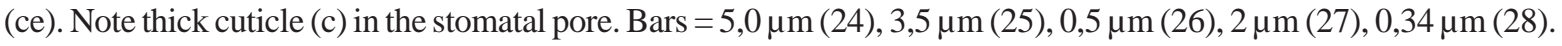


bainha dupla (XyMS+) é típica de espécies formadoras de aspartato (tipos NAD-ME e PCK). A disposição centrífuga dos cloroplastos na bainha parenquimática sugere que são do tipo PCK (Ellis \& Fulls 1980).

A presença de células incolores no mesofilo é referida por Watson \& Dallwitz (1992) como uma característica presente em espécies pertencentes ao gênero Tristachya. No entanto, tais células não foram observadas em Tristachya leiostachya.

Entre as características epidérmicas observadas neste trabalho, a mais relevante e segura para distinguir as duas espécies é a distribuição dos tricomas tipo espinho na superfície adaxial (antrorsos em Loudetiopsis chrysothrix e antrorsos e retrorsos em Tristachya leiostachya), sendo esta particularidade aqui registrada pela primeira vez. Algumas características da epiderme foliar, como silicificação generalizada das células, presença de ceras epicuticulares, ocorrência de estômatos em sulcos na superfície adaxial e diferenças no grau de sinuosidade das células da epiderme, apresentam reconhecida importância ecofisiológica e podem estar associadas com economia de água (Begg 1980).

Com relação às características anatômicas da lâmina foliar em seção transversal, várias particularidades observadas como o padrão de distribuição do esclerênquima subepidérmico associado aos feixes vasculares e no bordo; o padrão de vascularização, incluindo o tamanho e a distribuição dos feixes vasculares e o contorno dos vasos do metaxilema; as características do mesofilo, principalmente o número de estratos celulares do clorênquima em torno dos feixes vasculares e ausência/presença de células incolores, são de valor diagnóstico e podem, em conjunto, auxiliar na delimitação de Loudetiopsis chrysothrix e Tristachya leiostachya.

Agradecimentos - À Dra. Hilda Maria Longhi-Wagner, pela identificação do material botânico, à Fapesp: Programa Biota (Processo 00/12469-3), pelo apoio financeiro, e à Pró-Reitoria de Pós-Graduação e Pesquisa da Universidade Estadual Paulista pela bolsa de mestrado à primeira autora.

\section{Referências bibliográficas}

BAKER, E.A. 1982. Chemistry and morphology of plant epicuticular waxes. In The plant cuticle (D.F. Cutler, K.L. Alvin \& C.E. Price, eds.). Academic Press, London, p.139-165.

BEGG, J.E. 1980. Morphological adaptations of leaves to water stress. In Adaptation of plants to water and high temperature stress (N.C. Turner \& P.J. Kramer, eds.). John Wiley \& Sons, New York, p.33-42.
BROWN, W.V. 1958. Leaf anatomy in grass systematics. Botanical Gazette 119:170-178.

BROWN, W.V. 1975. Variations in anatomy, associations, and origins of Kranz tissue. American Journal of Botany 62:395-402.

BROWN, W.V. \& JOHNSON, S.C. 1962. The fine structure of the grass guard cell. American Journal of Botany 49:110-115.

CAMPOS, A.C. \& LABOURIAU, L.G. 1969. Corpos silicosos de gramíneas dos cerrados II. Pesquisa Agropecuária Brasileira 4:143-151.

ELLIS, R.P. 1976. A procedure for standardizing comparative leaf anatomy in the Poaceae. I. The leaf-blade as viewed in transverse section. Bothalia 12:65-409.

ELLIS, R.P. 1977. Distribution of the Kranz syndrome in the southern African Eragrostoideae and Panicoideae according to bundle sheath anatomy and citology. Agroplantae 9:73-110.

ELLIS, R.P. 1979. A procedure for standardizing comparative leaf anatomy in the Poaceae. II. The epidermis as seen in surface view. Bothalia 12:641-671.

ELLIS, R.P. \& FULLS, J.C.V. 1980. Photosynthetic pathways and the geographical distribution of grasses in south west Africa/Namibia. South African Journal of Science 76:307-314.

FIGUEIREDO, R.C.L \& HANDRO, W. 1971. Corpos silicosos de gramíneas dos cerrados V. In III Simpósio sobre o cerrado (M.G. Ferri, coord.). Edgard Blücher Ltda, São Paulo, p.215-231.

HATTERSLEY, P.W. 1986. Variations in photosynthetic pathway. In Grass systematics and evolution (T.R. Soderstrom, K.W. Hilu, C.S. Campbell \& M.E. Barkworth, eds.). Smithsonian Institution Press, Washington, p.49-64.

IHLENFELDT, H.D. \& HARTMANN, H.E.K. 1982. Leaf surfaces in Mesembryanthemaceae. In The plant cuticle (D.F. Cutler, K.L. Alvin \& C.E. Price, eds.). Academic Press, London, p.397-423.

JOHANSEN, D.A. 1940. Plant microtechnique. McGraw-Hill, New York.

JOHNSON, S.C. \& BROWN, W.V. 1973. Grass leaf ultrastructural variations. American Journal of Botany 60:727-735.

KRAUS, J.E. \& ARDUIN, M. 1997. Manual básico de métodos em morfologia vegetal. Edur Seropédica.

KAUFMAN, P.B., BIGELOW, W.C., PETERING, L.B. \& DROGOSZ, F.B. 1969. Silica in developing epidermal cells of Avena internodes: electron microprobe analysis. Science 166:1015-1017.

LONGHI-WAGNER, H.M. 2001. Tribo Arundinelleae. In Flora fanerogâmica do Estado de São Paulo, Poaceae. (M.G.L. Wanderley, G.J. Shepherd \& A.M. Giulietti, coords.). Fapesp, Hucitec, São Paulo. 1, p.119-123.

LYSHEDE, O.B. 1982. Structure of the outer epidermal wall in xerophytes. In The plant cuticle (D.F. Cutler, K.L. Alvin \& C.E. Price, eds.). Academic Press, London, p.87-98.

METCALFE, C.R. 1960. Anatomy of monocotyledons. I. Gramineae. Claredon Press, Oxford. 
REYNOLDS, E.S. 1963. The use of lead citrate at high ph as an electron-opaque stain in electron microscopy. Journal Cell Biology 17:208.

SENDULSKY, T. \& LABOURIAU, L.G. 1966. Corpos silicosos de gramíneas dos cerrados I. Anais da Academia Brasileira de Ciências 38:159-185.

SHIELDS, L.M. 1951. The involution mechanism in leaves of certain xeric grasses. Phytomorphology 1:225-241.

SILBERBAUER-GOTTSBERGER, I. 1984. Fruit dispersal and trypanocarpy in Brasilian cerrado grasses. Plant Systematics and Evolution 147:1-27.
SÖNDAHL, M.R. \& LABOURIAU, G.L. 1970. Corpos silicosos de gramíneas dos cerrados IV. Pesquisa Agropecuária Brasileira 5:183-207.

WATSON, M.L. 1958. Staining of tissue sections for electron microscopy with heavy metals. Journal Biophysical Biochemical Cytology 4:475.

WATSON, R.W. 1942. The effect of cuticular hardening on the form of cuticular cells. New Phytologist 41:223-229.

WATSON, L. \& DALLWITZ, J.M. 1992. The grass genera of the world. CAB Internacional,Wallingford. 